\title{
Assessing the Effectiveness of Scientific Illustration as a Learning Tool in the Classroom through Self Regulated Learning (Srl)
}

\author{
A. Sevarkodiyon, Dr. Mrs. M. Parimalafathima \\ Research scholar Alagapap University Alagappa University Karaikudi \\ Assistant Professor Alagapa University College of Education Alagappa University Karaikudi
}

\begin{abstract}
This article deals with the most effect models methods and process in the teaching learning process called scientific illustration technique is used as a tool in the teaching learning process. This tool is installed with a new strategy called self regulated learning this study includes 20 students from Government high school in Kalaiyarkoil block district Researchers adopted two activities i.e 1. Balancing equation 2. Lattice method through illustration technique with self regulated learning. As a result of the study it was performed that the illustration technique through self regulated learning improve the teaching learning process.
\end{abstract}

The scientific illustration is a part our classroom's culture Researchers interested about the pilot program created by illustrators Parrica Ferrer and joseph E trumpey Ferrer \&Trumpey (1999) created a pilot project through which they taught observational drawing to third grade and fifth grade students. The researchers selected a topic on Assessing the effectiveness of scientific illustration as a learning tool in the classroom through self regulated learning. Through a learning sequence they developed Ferrer and Trumpey (1999) taught students how to observe subjects how to take visual notes, how to discuss their observations with their peers, how to apply new knowledge to new drawings, and how to continuously assess their understanding of a subject. Ferrer and trump[ey (1999) measured learning gains using an assessment tool that was administered three times during the sequence and once after the sequence was completed. The fourth assessment was administered to determine how much information students retained one week later.

\section{Importance of Illustration}

Illustration has always been a vital part of the development of scientific understanding long before that invention of photography all scientific sequences were recorded through drawing.

Even in the photographical digital age illustration plays an important role in science understanding and communication from medical drawings to scientific diagrams illustrations aims to convey important scientific information to its intended audience.

Through creating illustrations children learn not only to look more closely at their subject but also to communicate the results of their enquires experiments observation research, scientific facts and theories to others. creating high quality visual outcomes raises condense shares knowledge more widely, can be used for assessment as well as dissemination through assemblies school displays and parents evenings.

Combining illustration and science learning support visual learners and creative thinkers a new angle on science learning is promoted and high quality illustrations can actually become science resources as in our examples from the schools.

\section{Illustrations through self regulated learning}

Creating illustration, children can learn the concept without the help of teacher. They are in a position to learn the concept their own style $100 \%$ learning achievement takes place with self regulated learning.

Self regulated learning is the self directive process by which learners transform their mental abilities into academic skills (Zimmerman 2002, P.65) self regulated learners often have effective study strategies persistence and the ability to determine what strategies are needed to do well in a content are needed to do well in a content area. Researchers have also found that goals play an important role in self regulated learning (Ridely, Schutz, Glanz \&Weinstein 1992) Students who have specific goals and are self regulated learners will more than likely reach their goals because they have effective study strategies persistence and the ability to determine what strategies are needed to meet these goals (Wolters 1998; Schunk,2005) According to Zimmerman the skills inherent to self regulated learning include setting specific goals adopting strategies for attaining goals, using time management skills, monitoring performance and managing social and psychical contexts. Students who attend class regularly, hand in all assignments and spend time studying effectively for tests will often do well in classes however, students who are not self regulated may not have the motivational or metacognitve skills to be effective academically. Based on students attitudes and performance instructors can 
often tell the differences between students who are self regulated learners and those who are not (Boekaerts 1996; Zimmerman)

\section{Activity :1 Picture Card Technique (PCT)}

Motivation

The co investigator asked all the VIIth students form a group among and he explained the balancing equation and he explained the PCT and gave importance of equation students are asked to listen carefully on this such as

Front /Back

$\mathrm{Mg}-$ colour

$\mathrm{O}_{2}$-Flame

S-Colour

C-c-colour

$\mathrm{Hg}$-silver form

Cl-Water

K-colour

I-Colour

\section{C4 Activity with the holp of PCT- Chart}
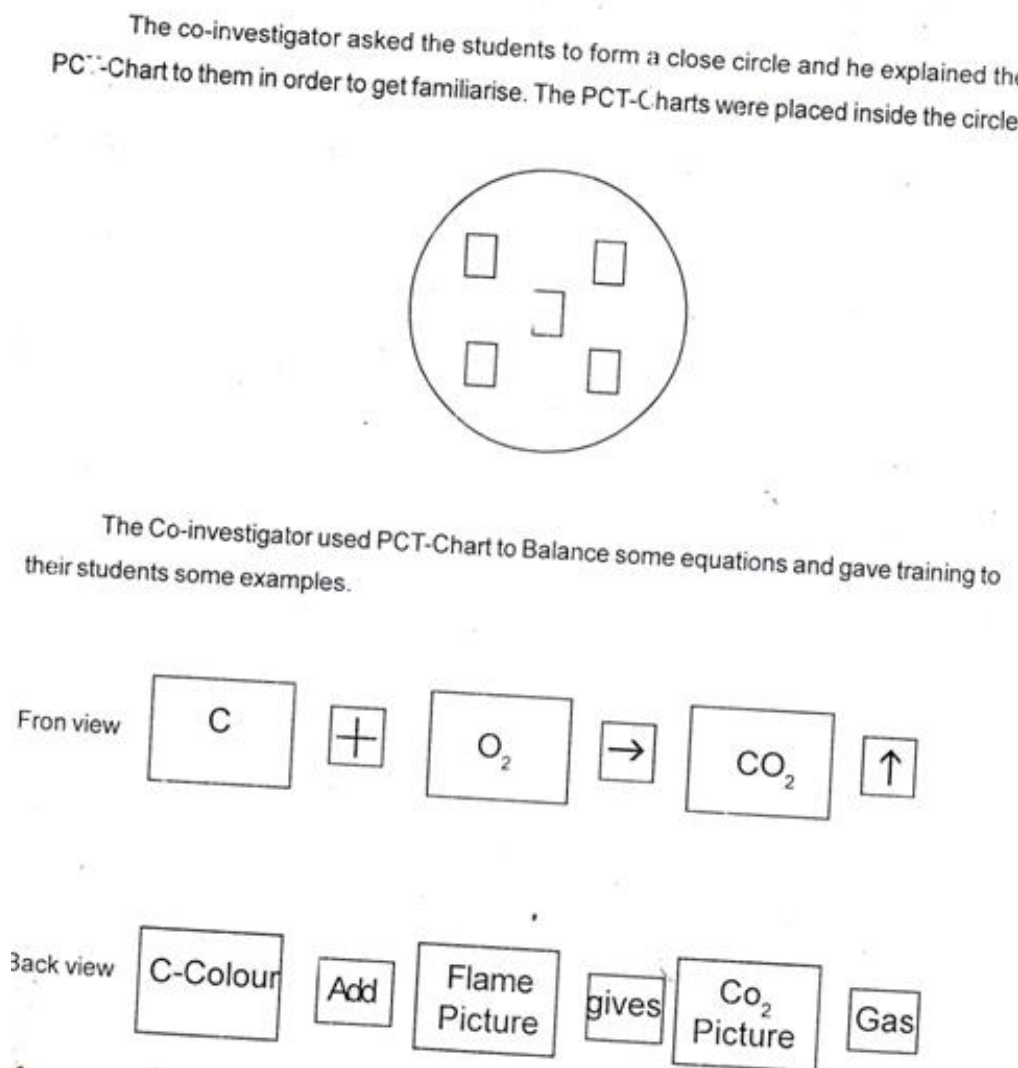

The following table shows mean standard deviation values of pre and post test score.

\begin{tabular}{|l|l|l|l|}
\hline Test & N & M & SD \\
\hline Pre test & 30 & 10.2 & 1.9 \\
\hline Post test & 30 & 12.55 & 3.2 \\
\hline
\end{tabular}

\section{N - Number Of Participants}

\section{SD- Standard Deviation}

\section{$M$-Mean Value}

The above table infer that the post test mean scores is 12.55 higher than pre test mean score (10.2) that is it clearly shows that the PCT chart facilities learners level in undertaking the balancing concept.

Moreover the standard deviation is also varies from 1.9 to 3.2 in the pre and post test score This is also giving more positive approach as said earlier. 


\section{Activity 2: Lattice method for multiplication}

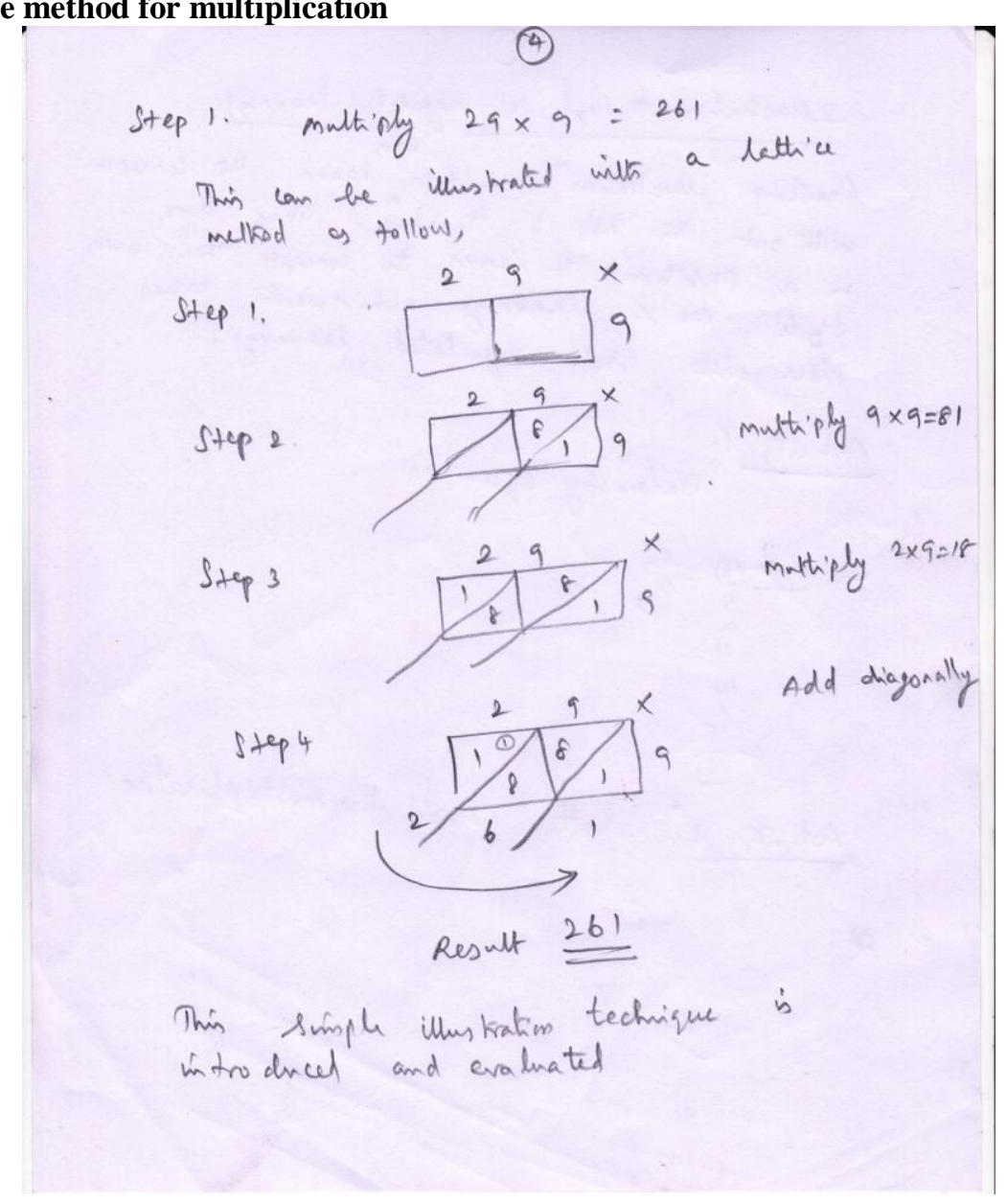

III. Analysis

\begin{tabular}{|l|l|l|l|}
\hline \multicolumn{1}{|c|}{ TEST } & \multicolumn{1}{c|}{ N } & \multicolumn{1}{c|}{ MEAN } & \multicolumn{1}{c|}{ SD } \\
\hline PRE ETST & 20 & 9.2 & 1.7 \\
\hline POST ETST & 20 & 12.55 & 3.2 \\
\hline
\end{tabular}

From the above table it infers that the post test mean is (12.55) higher than the test mean score (9.2) That is it clearly shows that the lathic illustration method is more effective than ordinary method.

\section{Conclusion}

The above said illustrations i.e balancing equation 2. Lattice method for multiplication are more effective than ordinary method of teaching. This type of illustration strengthen the teaching learning process. Further we can illustrate all other concepts in the teaching learning process.

\section{Reference}

[1]. Ferre Partica and joseph E Trumpey 1999 Assessing the effectiveness of scientific illustration as a learning tool in the elementary school classroom. Journal of Natural science illustration 391) 33-42.

[2]. Aam M.Gale A, Brown M. Khan Al (2010). The importance of human skills in project management professional dev elopement . Internet J.Managing pproject Bus. 3(3):495+516

[3]. Bronfenbrenner U.(1979) The Ecology of Human Development 3 Experiments by Nature and Design (Harvard University Press, Cam-bridge, MA)

[4]. Levasseur RE (1991) People skills: Self-awareness- A critical skill fro MS OR professionals, interfaces 21(1): 130-133. 